\title{
THE LOAD TESTING AND NUMERICAL VERIFYING OF THE PRECAST PRESTRESSED GIRDER
}

Precasting can solve complicated structural details, ambitious demands to quality of surface arrangements and manage hard terms filling at present. The prestressed precast girders are produced to $30.0 \mathrm{~m}$ span and are distributed for the realization of big shopping centers. The design and realization of the prestressed precast tie-beam for a skeleton system is presented in this paper. The experimental and numerical analyses were performed to verify the safety and reliable acting of the girder for the next service.

\section{Introduction}

The design, realisation and experimental testing of the prestressed precast tie-beam for the skeleton system is presented in this paper. Similar tie-beams are being produced to the span of $30.0 \mathrm{~m}$ and applied in the up to date big shopping centres. The experimental testing of the girder was applied on the new technological stressing bed that was constructed in the working plant of Prefa Sucany. The Prefa company started to produce precast rod elements for long span in 2004. Sufficient load carrying capacity for designed and for ultimate load level was approved as the main goal of the experiment. The experimental results were compared with the numerical ones gained from the nonlinear FEM analysis using the ATENA program system.

Precasting is the important component of the building production in civil engineering. Development in precast elements is being done hand in hand with the improvement of material base and structural systems. Complicated structural details, ambitious demands to quality of surface arrangements and a sharp time schedule of work can be satisfied using precasting technology at present. The modern technologies of self compacting concrete (SCC), high performance concrete (HPC) and light weight concrete (LWC) are gradually applied in practice for the precast elements.

The company Prefa Sucany had produced thin slab prestressed elements already in the past. The existing stressing bed with $250 \mathrm{t}$ prestressing capacity was changed to the new one with the length of $84 \mathrm{~m}$ and $1000 \mathrm{t}$ prestressing capacity in the year 2004. The company started to produce some rod types of precast prestressed elements for the skeleton and roof systems, mainly for new shopping centres. Rectangular, I, TT, or T shapes are commonly used shapes of girders.

The extension of production of the new types of girders required verification of important physical and mechanical para- meters designed and manufactured precast prestressed elements. Experimental testing was carried out in the collaboration with the company Prefa Sucany, Inc., University of Zilina and company Projstar PK, Ltd. The research results are presented in the report [3].

One of such precast tie-beams which were distributed for the shopping centre Kaufland was chosen for experimental and numerical testing.

The original manufactured girder with the length of $24.0 \mathrm{~m}$ was reduced in compliance with the purpose of the experiment to the length of $18.0 \mathrm{~m}$. The general aims of the experimental test can be specified as follows:

- to verify the transferring of prestressing force to concrete element and prestressing losses,

- to prove a sufficient load carrying capacity of the girder for the designed load level that was simulated by the real roof coat, see Fig. 1, and Tab. 1,

- to observe the girder behaviour after a crack propagation,

- to achieve the ultimate limit state of the girder.

The proposed skeleton system is manufactured in the $12 \times 18 \mathrm{~m}$ module and the 4 roof beam being reacted on the girder in $1 / 3$ of the span. The values of the load according to standard [1] were proposed:

- the permanent load consists of the self-weight of the girder, the weight of concrete roof beams with a trapezium cross-section with the basics of 200 and $300 \mathrm{~mm}$ and the depth of $700 \mathrm{~mm}$, the anchored foil, thermal insulation $80 \mathrm{~mm}+160 \mathrm{~mm}$ fumeinsulation and trapezoidal plate (the Ranilla Ran $1 \mathrm{~mm}$ ).

- a variable load due to electricity distributions, air-condition, etc. The climatic load consists of snow action for the IV snow area, according to [1] and the suck action of the wind.

\footnotetext{
* Martin Moravcik

Department of Structures and Bridges, University of Zilina, Faculty of Civil Engineering, Komenskeho 52, 01026 Zilina, Slovakia,

E-mail: Martin.Moravcik@fstav.uniza.sk
} 
Resulted values of the point action $\mathrm{F}$ and internal forces are presented in Tab. 1.

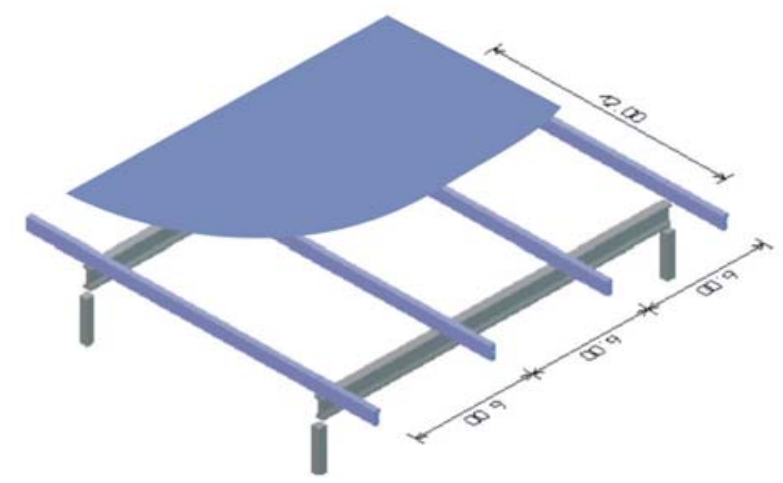

Fig. 1 Scheme of the investigated girder in skeleton system

Designed values of the load and internal

Table 1 forces for the tie-beam

\begin{tabular}{|l|c|c|c|}
\hline & $\mathrm{F}[\mathrm{kN}]$ & $\mathrm{M}[\mathrm{kNm}]$ & $\mathrm{V}[\mathrm{kN}]$ \\
\hline characteristic value & 239.30 & 1570.48 & 298.19 \\
\hline design value & 307.44 & 2135.35 & 372.13 \\
\hline
\end{tabular}

\section{Basic parameters of the girder}

Considering spatial and manipulation possibility the girder with $18 \mathrm{~m}$ span was used for the testing. The girder was designed according to the standard [2]. It has to satisfy the stress conditions and crack width for an element of "second category". That means $0.5 \mathrm{MPa}$ compress stress at least in the permanent tension concrete fibres due to the permanent load action. The computer program "PresBeam" was developed for design of precast prestressed girders.

Depth of the investigated girder is $1050 \mathrm{~mm}$ and other geometrical parameters can be seen in Fig. 2. The designed concrete quality is C50/60. Self-weight of the girder is $12.45 \mathrm{t}$. The real average concrete cube strength was $63.9 \mathrm{MPa}$. It was 35 days after transferring prestressing to the concrete. The R-type cement was used. Concrete strength had the value of $46.8 \mathrm{MPa}$ in the time of prestressing transfer. Prestresing elements consist of 14 tendons LSA $15.5 / 1800 \mathrm{MPa}$. The tendons are arranged to the raster $50 \times$ $50 \mathrm{~mm} 4$ tendons are included to the bottom 3 rows (tendons A) and the 2 tendons belong to the top row, see Fig. 2. Two other tendons in the bottom row were separated using a greased polyethylene tube of the $2.0 \mathrm{~m}$ length (tendons B). The prestressing force was designed $186.8 \mathrm{kN}$ and applied using the PAUL system.

Profiles of $\varphi 10$ and $16 \mathrm{~mm}$ of the type (R) 10505 were used for the longitudinal girder reinforcement, and for stirrups the profile of $\varphi 10 \mathrm{~mm}$ over $250 \mathrm{~mm}$ was used. The distance was reduced to $100 \mathrm{~mm}$ above abutments and manipulate elements for stirrups.

\section{Test arrangement}

The girder was continually observed from the time of tendons stressing to the load test performing. The following parameters were scanned - the prestressing force $(P)$, the vertical deflections $(f)$, the concrete strain $(\epsilon)$, the temperature $(t)$, the crack width $(w)$ and a possible tendon slip $(\Delta)$. Possible settlement of abutments was geodetically checked. The prestressing force was recorded using elastomagnetic sensors, Fig. 4b), using Projstar PK system. One sensor was located on top tendon and one was fixed on bottom tendon. Experimentally and theoretically achieved results of the actual prestressing force are presented in Tab. 2 and the registered data from elastomagnetic sensors can be seen in Fig. 3.

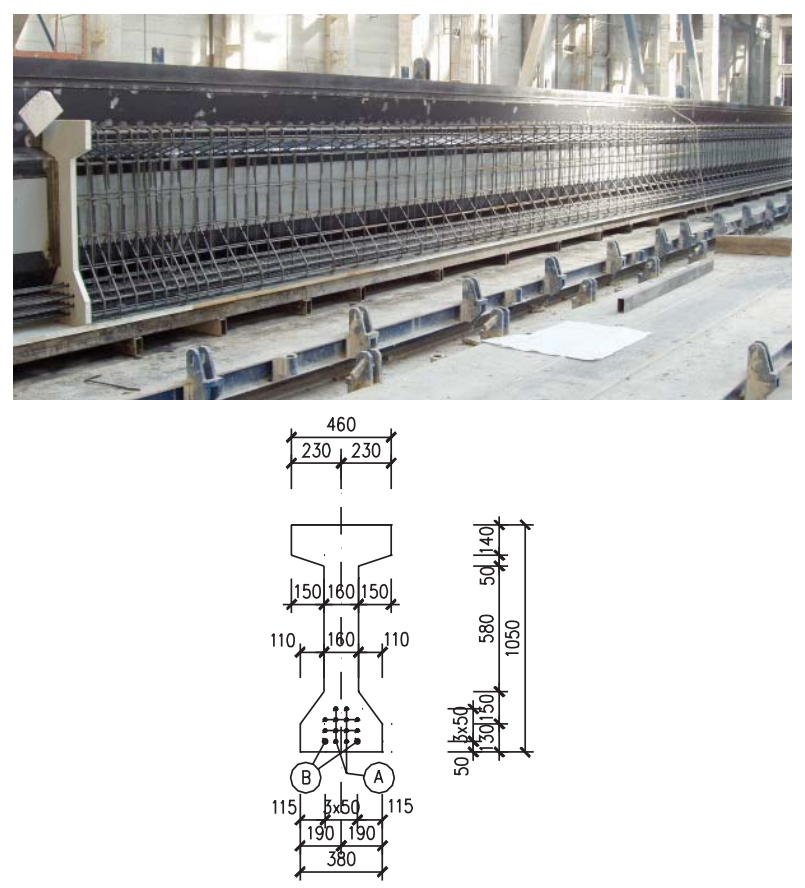

Fig. 2 Reinforcement and the cross section of the girder

Sucany- nosník 18 m - napínanie lán

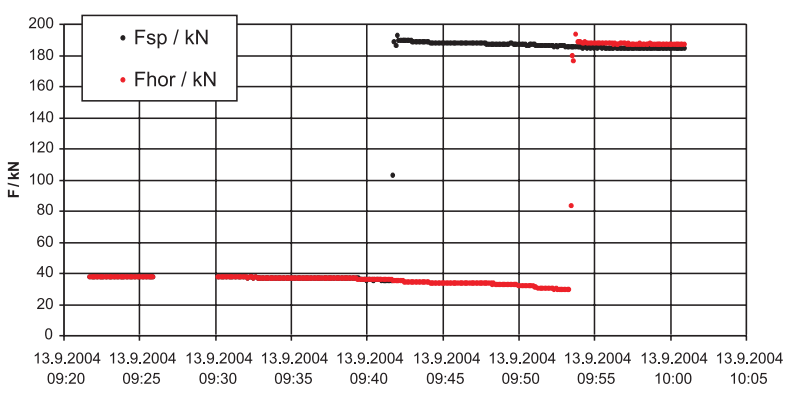

Fig. 3 Stressing force course in the tendons 
Prestressing force measured during prestressing and transferring process

Table 2

\begin{tabular}{|c|c|c|c|c|c|c|c|}
\hline Force $(\mathrm{kN})$ & $\begin{array}{c}\text { prestressing. } \\
\text { theoretic. }\end{array}$ & $\begin{array}{c}\text { prestressing } \\
\text { recorded }\end{array}$ & $\begin{array}{c}\text { ratio } \\
(-)\end{array}$ & $\begin{array}{c}\text { transferring } \\
\text { theoretic. }\end{array}$ & $\begin{array}{c}\text { transferring } \\
\text { recorded. }\end{array}$ & $\begin{array}{c}\text { ratio } \\
(-)\end{array}$ & $\begin{array}{c}\text { immediate } \\
\text { losses }\end{array}$ \\
\hline bottom tendon & $186.8 \mathrm{kN}$ & $184.3 \mathrm{kN}$ & 0.986 & $167.5 \mathrm{kN}$ & $158.2 \mathrm{kN}$ & .0 .944 & $26.1 \mathrm{kN}$ \\
\hline top tendon & $186.8 \mathrm{kN}$ & $186.9 \mathrm{kN}$ & 1.001 & $171.1 \mathrm{kN}$ & $161.0 \mathrm{kN}$ & 0.941 & $25.9 \mathrm{kN}$ \\
\hline
\end{tabular}

The resistance sensors of the type NovoTechnik TR with the range of 50 or $150 \mathrm{~mm}$ were used for vertical deflection measuring and for checking the possible tendon slip. Vertical deflection was scanned in 11 points equally distributed along the span, according to Fig. 4a). The concrete strain monitoring was realised using common Hollan mechanical strain gauger and the strain gauges of type HBM 50/120LY41, see Fig. 4b). Five points were defined along the cross section depth, according to Fig. 4a). The crack width was monitored with magnifier with scale and photometric method using digital cameras (3MP and 10x zoom) was also used for crack width calibration.

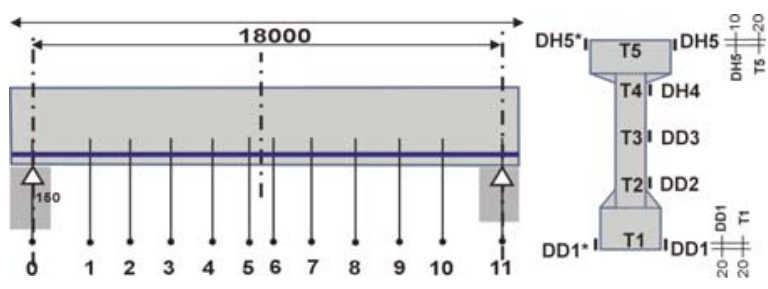

Fig. 4a) Measured points location for the deflection and concrete strains
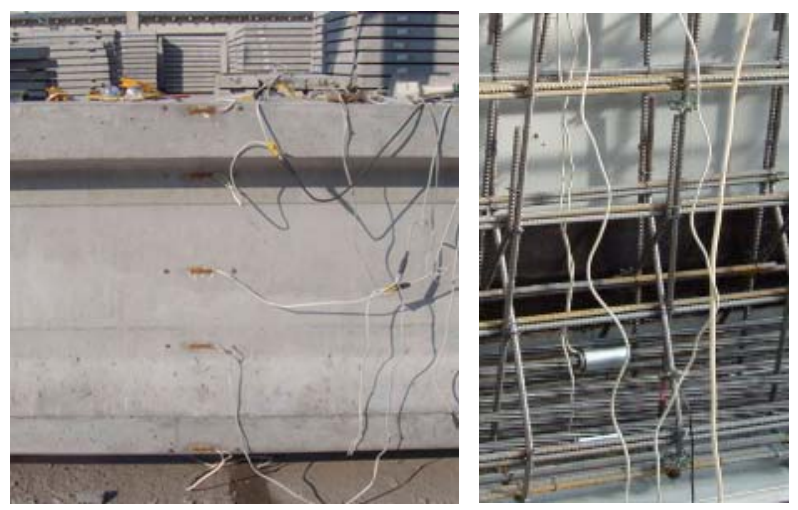

Fig. 4b) Strain gauges and elastomagnetic sensors

The girder was set on fixed abutments through the elastic bearings. The elastic bearings deformations were recorded too. The concrete panels with dimensions $2.0 \times 3.0 \times 0.15 \mathrm{~m}$ were used as loading elements. Their gravity was exactly determined using the suspension weight equipment. The average one panel gravity oscillated from 2.1 to 2.2 t. Load steps were realised incrementally without unloading steps. One load step includes loading by 4 panels equally assembled to 1 row, see Fig. 5. The 21 rows of panels and 15 load steps were finally performed.

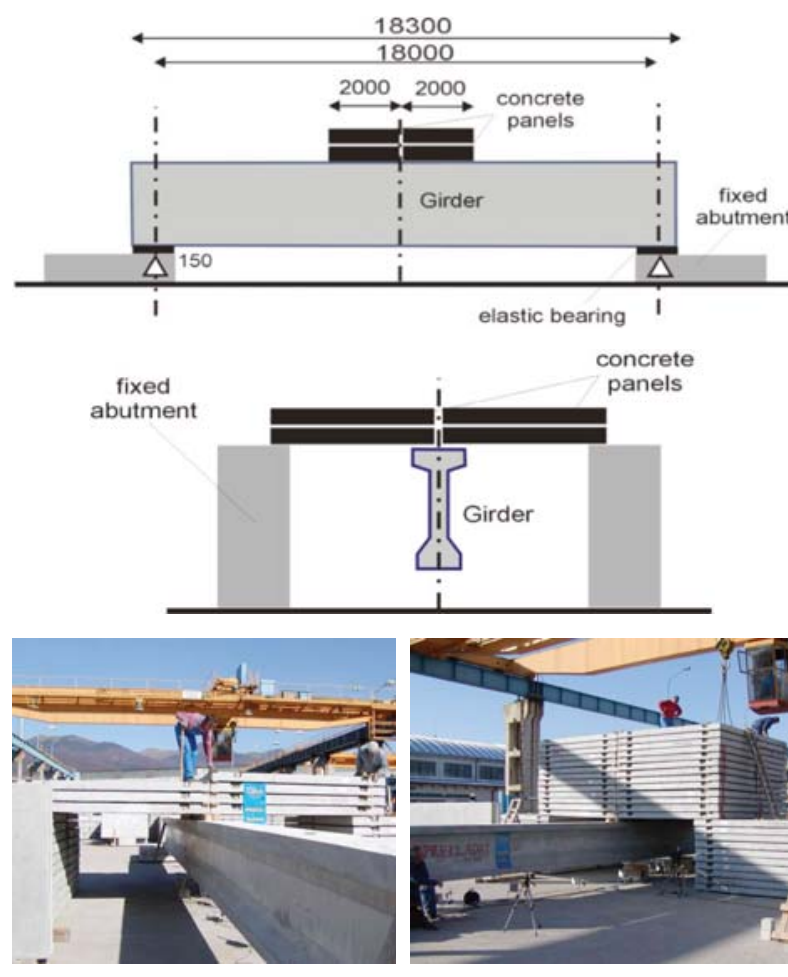

Fig. 5 Loading scheme of the girder

\section{Numerical analysis principles}

The nonlinear FEM computer program ATENA, [5] was used to analyse this problem to compare theoretical and experimental values of the above mentioned girder mechanical parameters. ATENA system enables to consider material and geometrical nonlinearities of concrete structures based on fracture mechanics and nonlinear solution principles.

The constitutive relations are formulated for the plane stress state. A smeared approach is used to model the material properties for cracks and the longitudinal and transversal reinforcement. In that concept the implemented material model SBETA, [5] was used for concrete element, see Fig. 6.

The material model SBETA includes the following effects of concrete behaviour:

- non-linear behaviour in compression including hardening and softening,

- fracture of concrete in tension based on the nonlinear fracture mechanics, 

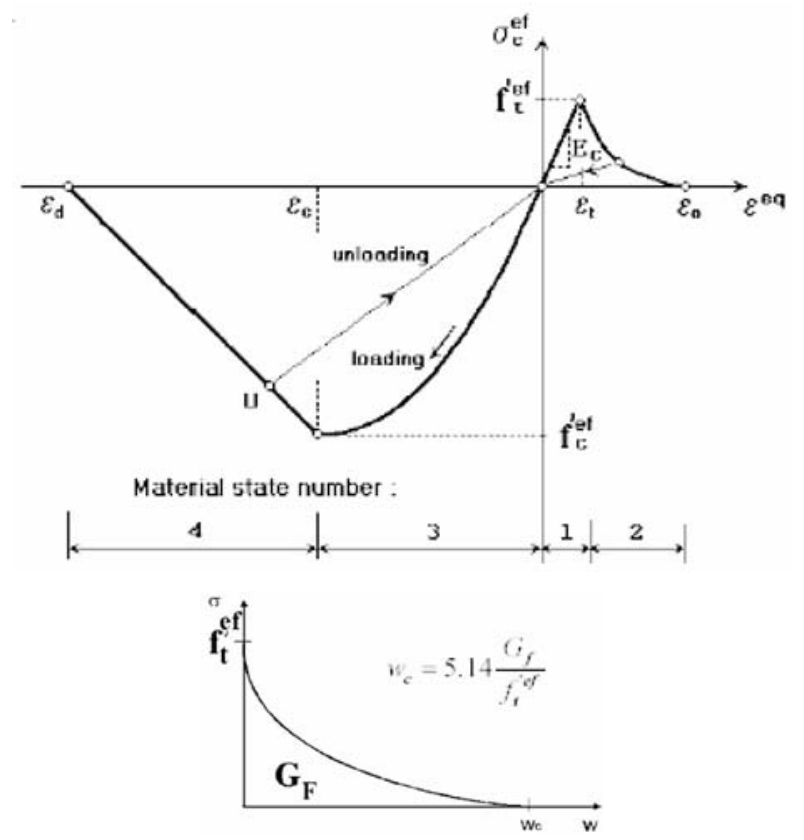

Fig. 6 Uniaxial stress-strain law for concrete - tension and compression.

- biaxial strength failure criterion,

- reduction of compressive strength after cracking,

- tension stiffening effect,

- reduction of the shear stiffness after cracking (the variable shear retention),

The perfect bond between concrete and reinforcement is assumed within the smeared concept. The exponential crack opening law and the fixed crack model was applied as a model of smeared cracks. Tendons are modelled as discrete elements and the bilinear stress-strain relationship for all reinforcement was applied.

\section{Results of theoretical and experimental analysis}

\subsection{Phase of prestressing application}

The measurement and numerical analysis of the deflection and the prestressing force transferred to the concrete were realised as first. The short-term losses were about $12 \%$ including the elastic deformation of concrete.

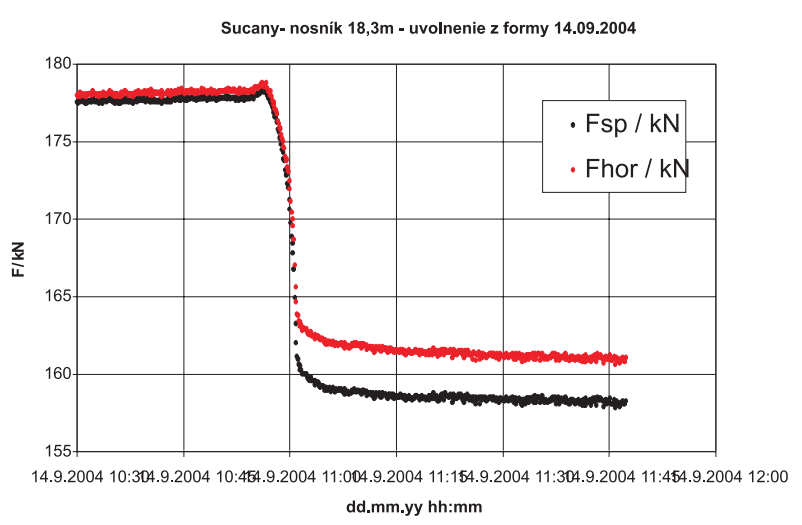

Fig. 7 Transferred prestressing force in bottom flange of the girder.

Real observed values of the camber along the longitudinal axis were gained immediately after the transferring time (around 24 hours) and their value was $44 \mathrm{~mm}$. It was higher value than the designed value of $31 \mathrm{~mm}$, according to the Slovak standard [2], see Fig. 8. Several cracks were detected on the upper flange in the third length on the both side of girder. Their width increased the values up to $0.1 \mathrm{~mm}$. Therefore the numerical nonlinear analysis for the deflection applied on a relatively young concrete deflection was performed including crack propagation effect in the concrete. The value of deflection was $42 \mathrm{~mm}$. Cross section was divided to 3 sections - upper flange, the web and the bottom flange respecting to the concrete modulus of elasticity distribution along cross section, see Tab. 3. Apart from the modulus the compression and tension concrete strength have been changed depending on location in the cross section. The concrete modulus of elasticity was considered as a standard value $[2,4]$ and values with respect to the actual time $(t)$ adjusted to the concrete temperature $\left(t_{T}\right)$ and the cement type $(s)$, [6]. Two types of the used cement were compared and the time of 1 day was considered in the analysis. The modulus was expressed by the following relationship,

$$
E_{c i}(t)=\beta_{c c}(t)^{0.5} \cdot E_{c o}\left[f_{c m} / f_{, c m o}\right]^{0,3},
$$

where $\beta_{c c}(t)=e^{\left[s \cdot\left[1-\left(28 /\left(t_{T} / t 1\right)\right) 0.5\right]\right.}$

\subsection{The load test phase}

Experimental results of the vertical deflection due to the load action increase are presented in Fig. 10. The girder deflection was

Concrete modulus of elasticity depending to the temperature and the cement type

Table 3

\begin{tabular}{|c|c|c|c|c|c|c|}
\hline \multirow{2}{*}{ Location } & \multicolumn{3}{|c|}{ Cement RS $(52,5)$} & \multicolumn{3}{c|}{ Cement N, R $(32,5,42,5)$} \\
\cline { 2 - 7 } & $\left.T_{-} t_{i}\right)\left[^{\circ}\right]$ & $f_{c c m}(t)[\mathrm{MPa}]$ & $E_{c i}(t)[\mathrm{GPa}]$ & $T\left(_{-} t_{i}\right)\left[^{\circ}\right]$ & $f_{, c m}(t)[\mathrm{MPa}]$ & $E_{c i}(t)[\mathrm{GPa}]$ \\
\hline upper flange & 27.0 & 31.63 & 21.37 & 27.0 & 26.53 & 18.56 \\
\hline web & 29.5 & 33.20 & 22.21 & 29.5 & 28.18 & 19.49 \\
\hline bottom flange & 37.7 & 38.63 & 24.78 & 37.7 & 33.44 & 22.34 \\
\hline
\end{tabular}



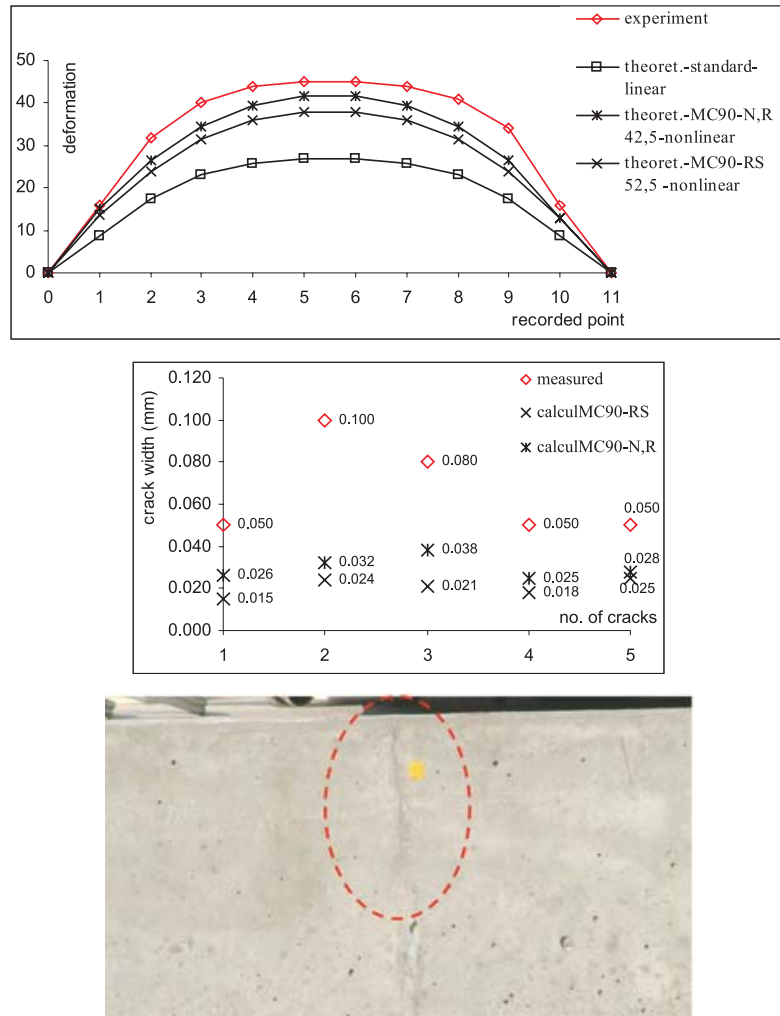

Fig. 8 Deflection and crack pattern at upper flange of girder, the real one crack at upper flange

analysed using ATENA system and standard approach according to [4], the relation (3) was used too. The principle of incremental stiffness reduction based on the average cross section curvature $(\kappa)$ was applied. Good coincidences between both of the theoretical values were observed. The theoretical value of critical bending moment according to EN is $M_{c r}=1590.76 \mathrm{kNm}$. Experimental bending moment was $M=1701.87 \mathrm{kNm}$ when the first visible bending crack was detected. After that stage when the first crack appeared the numerical values of deflection is more conservative comparing to the experimental ones.

$$
\kappa=\xi \kappa_{I I}+(1-\xi) \kappa_{I}
$$

The first crack of hair character with the length of $6 \mathrm{~cm}$ through all the bottom part of flange was developed in the distance

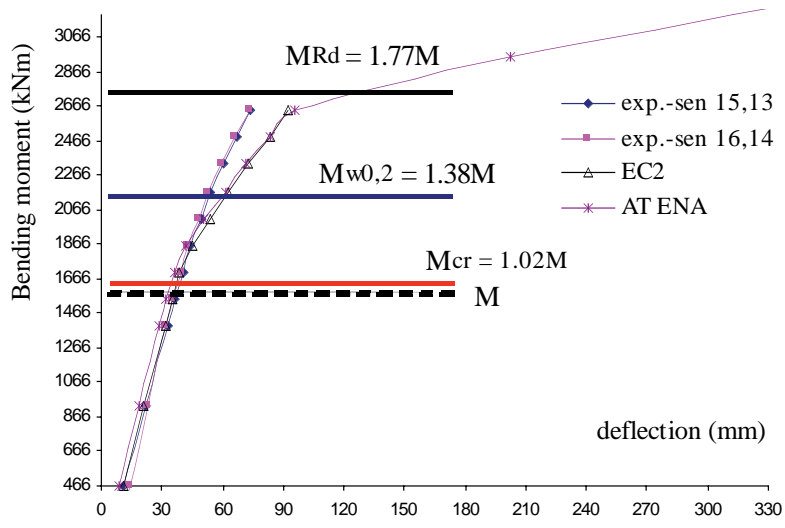

Fig. 10 Vertical deflection vs. bending moments $M$ in the middle span cross section

of around $70 \mathrm{~cm}$ from the middle cross section. Next bending cracks were propagated on both sides equally around the $500 \mathrm{~mm}$ distance. That distance was gradually decreased to $100 \mathrm{~mm}$ and cracks were grown to the compressed area, see Fig 10. The critical crack width of $0.2 \mathrm{~mm}$ for the serviceability limit stage [4] was reached between $10^{\text {th }}-11^{\text {th }}$ load steps and the corresponding bending moment level $M=2172,80 \mathrm{kNm}-2329.60 \mathrm{kNm}$, see Fig. 11a).

The crack width $(w)$ was calculated following the ATENA system and standard approach according to [4] and the relation (4) was used. Compared to the theoretical values of a crack width and experimental results the same course of all curves can be seen in Fig. 11b). The theoretical results according to [4] are more conservative than ATENA and the experimental ones.

$$
\begin{gathered}
w_{k}=s_{r, \max } \cdot\left(\epsilon_{s m}-\epsilon_{c m}\right), \\
\text { where } \epsilon_{s m}-\epsilon_{c m}=\frac{\sigma_{s}-k_{t} \cdot \frac{f_{c t, e f f}}{\rho_{p, e f f}} \cdot\left(1+\alpha^{e} \cdot \rho_{p, e f f}\right)}{E_{s}}
\end{gathered}
$$

The pattern of crack propagation on a real girder for the last load step is very similar to the numerical model sample, see Fig. 12. The values of distance between the cracks oscillate from 100 to $250 \mathrm{~mm}$.

The development of the force in tendons is presented in Fig. 14. The indication in Fig. 14, "P1r" means the tendon in the
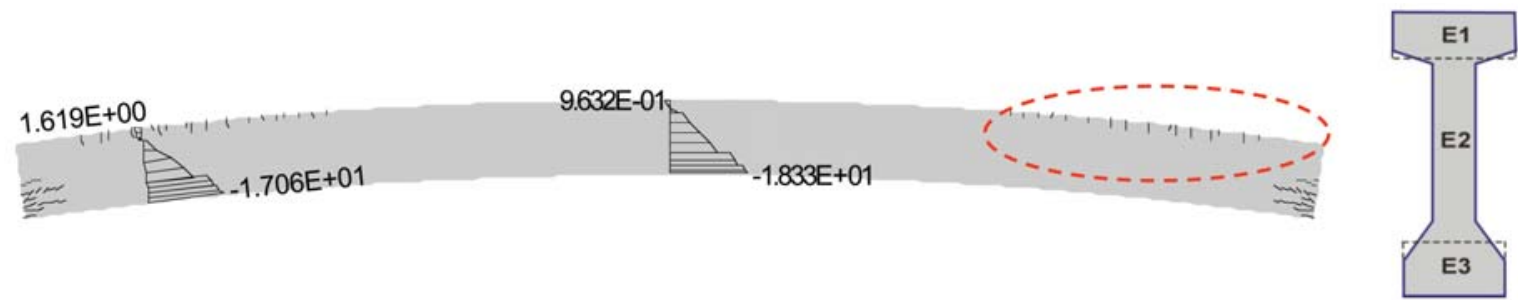

Fig. 9 Deflection, the crack pattern and normal stresses in the middle span section and section on the end of tendons separation length of the girder 

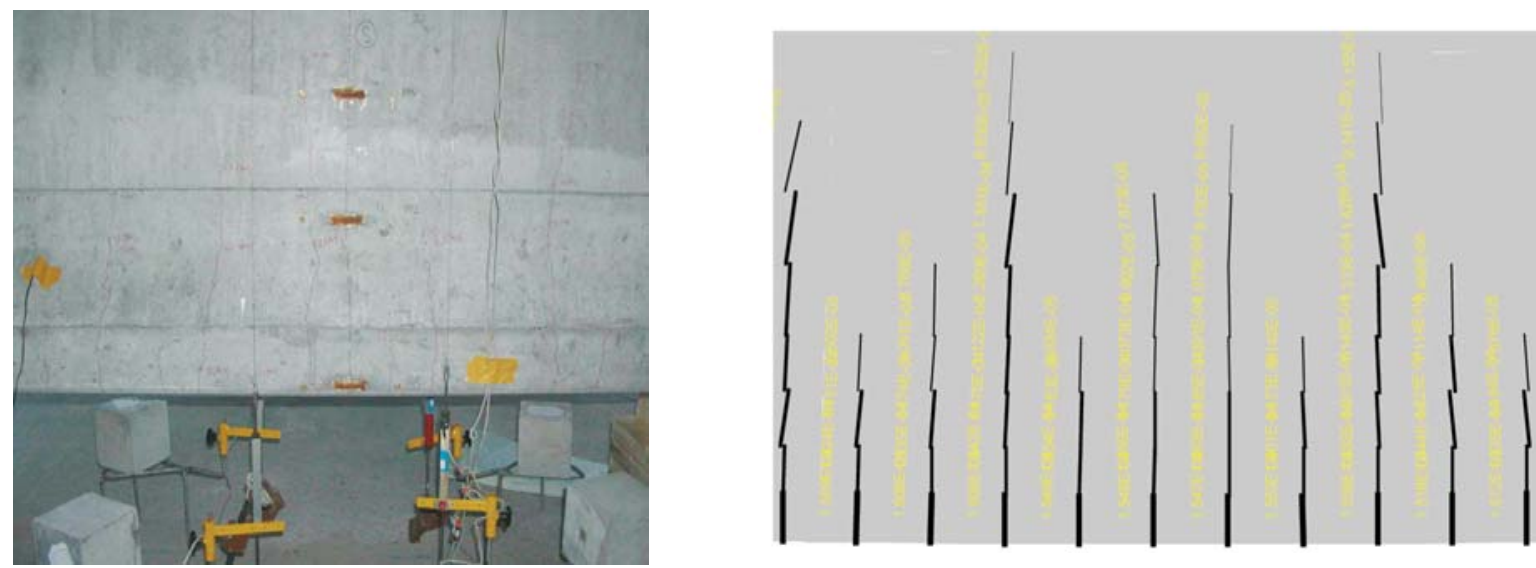

Fig. 11a) Crack propagation - experiment, ATENA - the 11. load step
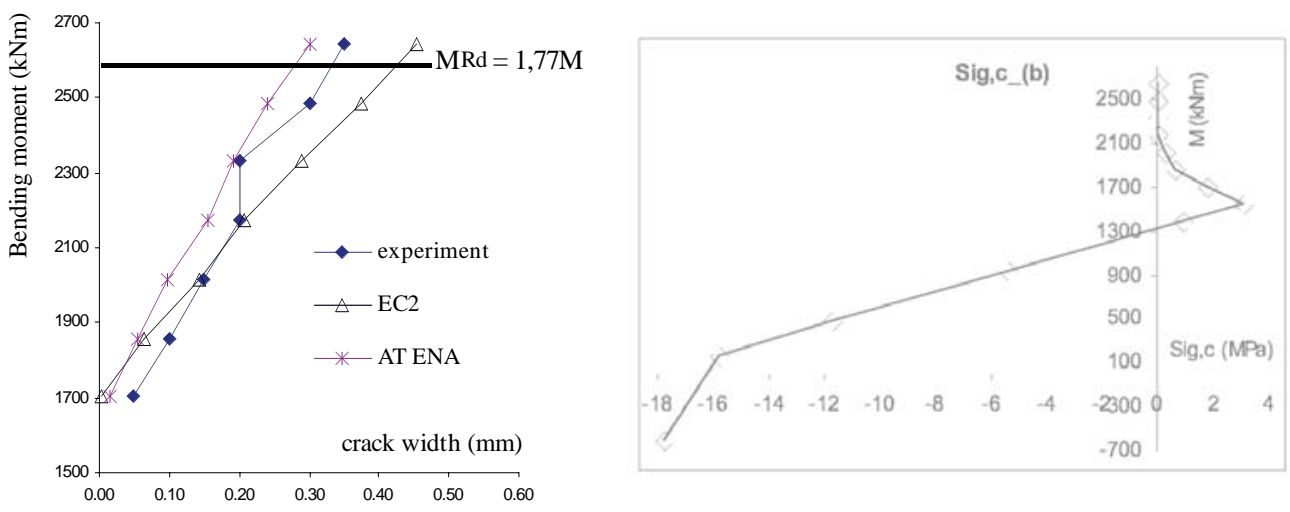

Fig. 11b) Crack width for 7. - 13. load steps and normal stress course at bottom fibres in the middle cross section

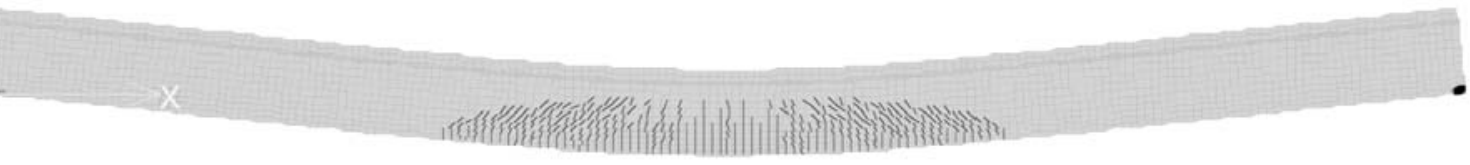

Fig. 12 Crack propagation in the real girder after load test and numerical model output - the last 15. load step

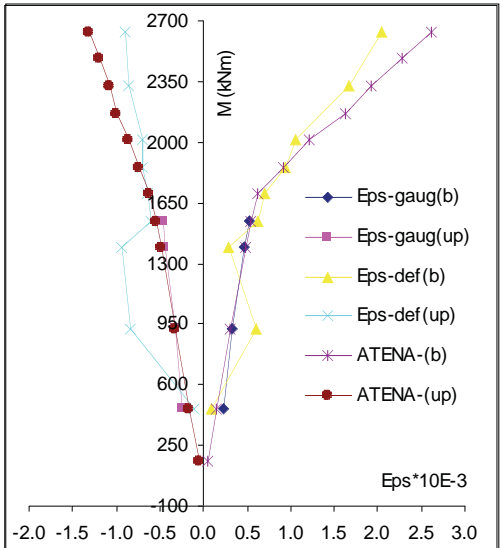

Fig. 13 The strain in edge fibres in the middle cross section - measured vs. theoretical values

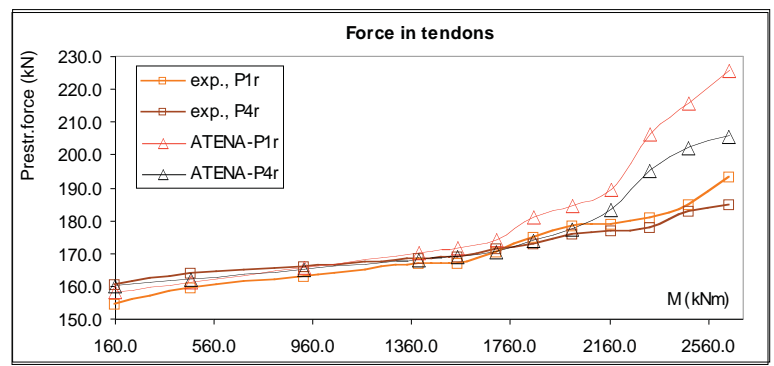

Fig. 14 Development of the force in observed tendons - measured vs. theoretical values

bottom row and "P4r" the tendon in the upper row. Proper conformity is apparent between the test and model particularly when the first crack was detected. After that point the numerical model was a little bit more conservative compared to tested values. It cor- 
responds with the above mentioned results of deflection and strains in the concrete. The theoretical rupture of the tendon should become on the level of $254.7 \mathrm{kN}$.

\section{Conclusions}

On the basis of the experimental testing and numerical analysis results the following conclusions can be formulated:

- The theoretical assumption of prestressing force transferring was fulfilled.

- The sufficient load carrying capacity of the girder was approved for designed load and manufactured tie-beams can be reliably used in practice.

- The ATENA system can be successfully used to simulate precast prestressed structural elements on the full scale of its material behaviour. The material model SBETA and a fixed crack model are useful for numerical modelling of such problems.

- The initial camber was higher than the theoretical one but the negative influence on consequential load carrying capacity and serviceability of girder was not observed. It is necessary to use the concrete modulus of elasticity adjusted with the influence of location, the time, the temperature and the type of cement for accurate deflection determination. The recommendation relation presented in $[2,4]$ enable appropriate to solve that problem.

- By $6 \%$ higher immediate prestressing losses in comparison with the theoretical values can be observed. It was caused by earlier prestressing transfer to concrete.

- The first visible hair crack was detected a little bit later than it was expected and the accurate reinforcement assured the expected crack distribution in concrete.

- The theoretical value of bending moment in the ultimate limit state $M_{R d}=2784.21 \mathrm{kNm}$ was exceeded over $M=3273.60 \mathrm{kNm}$ but the element did not reach a rupture.

\section{Acknowledgement}

The research work presented in this paper is supported by the VEGA agency 1/0348/03.

\section{References}

[1] STN 73 0035: Load action of building structures, SÚTN Bratislava 1993.

[2] STN 73 1201: Design of concrete structures, SÚTN Bratislava 1993.

[3] Moravcik, M.: Report from the load test of the precast prestressed beam of I shape for building structures, 2005, p. 1-18

[4] prEN 1992-1-1: Design of Concrete Structures - Part 1: General rules and rules for buildings, CEN 07/2002, Brussels.

[5] Cervenka Consulting: ATENA Program documentation, Theory, Prague, Oct. 2003,

[6] Commite Euro-International du Beton: CEB-FIP Model Code 1990, Thomas Thelford, 1991 